\title{
Thyroid function profile, and its association to consumption of cassava and Moringa stenopetala in pregnant women
}

\author{
Alemayehu Zekewos Golla \\ Biochemistry Unit, School of Medicine, Hawassa University, Hawassa, Ethiopia \\ Email: alemzeke@yahoo.com
}

Received 20 July 2013; revised 29 August 2013; accepted 16 September 2013

Copyright (C) 2013 Alemayehu Zekewos Golla. This is an open access article distributed under the Creative Commons Attribution License, which permits unrestricted use, distribution, and reproduction in any medium, provided the original work is properly cited.

\begin{abstract}
Background: Pregnancy is associated with the change in thyroid function. Thyroid function is also affected by goitrogenic substances in some plant foods, like cassava. Aim: This study aims to assess thyroid function status and its association to consumption of foods containing goitrogenic substances. Methods: A cross sectional study was done on a total of 65 pregnant women attending Sawla Health Center, South Ethiopia. Serum samples were collected and analyzed for TSH, total T4 and total T3 by using ELISA kit. Data on consumption of foods containing were obtained from food frequency questionnaire. Results: The median TSH of the first, second and third trimesters, respectively are $2.57,1.86$ and $2.42 \mathrm{mIU} / \mathrm{L}$, which are within the reference interval $(0.30-6.20 \mathrm{mIU} / \mathrm{L})$ of the test kit. The median total $\mathrm{T} 4$ values $(9.8,10.0$ and $10.3 \mu \mathrm{g} / \mathrm{dl}$ in the first, second and third trimesters, respectively) were also within the reference interval (4.8 - $11.6 \mu \mathrm{g} / \mathrm{dl}$ ) of the test kits. The median total T3 in the first $(2.60 \mathrm{ng} / \mathrm{ml})$ and third $(2.35 \mathrm{ng} / \mathrm{ml})$ trimesters were elevated, but it was within the reference interval $(0.69-2.02 \mathrm{ng} / \mathrm{ml})$ in the second trimester $(1.92$ $\mathrm{ng} / \mathrm{ml})$. Though statistically non-significant median TSH was increased in women grouped as cassava consumers and $M$. stenopetala consumers while median total T4 values were decreased in these groups. Conclusion: The study subjects have normal thyroid function as the median values of TSH and total T4 were within the reference interval of the test kit. Frequent consumption of cassava and Moringa stenopetala may affect thyroid function.
\end{abstract}

Keywords: Thyroid Function; Pregnancy; Cassava; Moringa stenopetala; Goitrogenic Substances

\section{INTRODUCTION}

The human thyroid gland generates two major hormones, thyroxine (T4) and triiodothyronine (T3) $[1,2]$. Thyroid hormones are made from tyrosine and iodine on thyroiglobulin molecule [3]. About $93 \%$ of the hormone produced by the thyroid follicles is $\mathrm{T} 4$ and the rest $7 \%$ is T3 [2]. Around $80 \%$ of T3 is formed in peripheral cells from enzymatic conversion of T4 [3]. Although T3 is less abundant in the circulation, it is about four times more potent than $\mathrm{T} 4[1,2]$.

Thyroid function is affected by various conditions, such as pregnancy, and iodine deficiency [4]. Pregnancy is associated with the marked changes in thyroid function, resulting from a combination of factors specific for pregnant state, such as the rise in thyroxine-binding globulin (TBG), the effect of human chorionic gonadotropin (hCG) on the maternal thyroid, and alteration in iodine requirement [5]. Total T4 and total T3 concentrations increase sharply in early pregnancy and reach plateau early in the second trimester, thereafter are maintained at a constant level until term $[4,5]$. The increase in total T4 and total $\mathrm{T} 3$ in early pregnancy is due to increased serum TBG in pregnancy, which also reaches plateau during midgestation [4,6-8]. The increased level of TBG during pregnancy is due to an increase in hepatic synthesis of TBG and an increase in sialylation that increases the half life of TBG. Both mechanisms are induced by increased concentration of estrogen during pregnancy $[5,7,9,10]$.

The rapid rise in the serum hormone-binding capacity tends to slightly decrease free hormone concentrations that demand thyroidal adjustment by throid stimulating hormone (TSH) stimulation of the gland. However, in healthy pregnant women with adequate iodine intake, an increase in serum TSH is not commonly observed $[5,11]$.

A placental hormone hCG starts to increase in serum 
beginning from early gestation. Various studies have shown that hCG stimulates thyroid hormone production from the thyroid gland, leading to a reciprocal decrease in serum TSH concentrations $[5,12,13]$. When hCG level reaches its peak, then decreases in serum level of TSH, showing that hCG has thyroid stimulating activity [5]. The thyrotropic action of hCG is due to its ability to interact with the TSH receptor. Upon interaction with TSH receptor, hCG enhances iodine uptake by thyrocytes and iodine organification [14]. The thyroid stimulating effect of hCG is believed to be attributed to the close structural relationship between $\mathrm{hCG}$ and $\mathrm{TSH}$, and between their receptors [15].

Substances, generally called goitrogens, will also affect thyroid function and may further aggravate the consequence of iodine deficiency. Some of these goitrogens occur in certain widely used food plants [16]. Cyanogenic glucosides, thioglucosides and thiocyanate ( $\mathrm{SCN}$ ) are the goitrogenic constitutes of these food plants [17]. Cassava contains high concentration of cyanogenic glucosides, particularly linamarin [18]. The goitrogenic activity of cassava is mediated by SCN formed by intestinal breakdown of cyanogenic glucosides and conversion to thiocyanate by the liver or residual cyanide $(\mathrm{CN})$ from incompletely detoxified products [19]. SCN and isoSCN can inhibit the uptake of iodine by thyroid gland and thyroid peroxidase, preventing formation of T4 [20,21].

Different studies have shown that goiter prevalence in Demba Gofa district is high [22]. This high goiter prevalence in the area may partly be attributed to consumption of foods containing goitrogenic substances. A study by Cherinet $e t$ al. has shown that total goiter prevalence was increased with increased rate of cassava consumption in three villages of the district [23]. Another study has shown that consumption of Moringa stenopetala (Alleko) more than two times per day was significantly associated with causation of goiter in the same district [24]. However, few biochemical studies have been done showing the pattern of thyroid function in different population groups, but not in pregnant women $[25,26]$. Thus, the aim of this study was to assess thyroid function profile and the effect of consumption of cassava and Moringa stenopetala on thyroid function of pregnant women.

\section{METHODS}

\subsection{Study Design and Sample Size}

The study was designed as cross sectional. A total of 69 pregnant women, attending Sawla Health Center for Antenatal Care (ANC), gave informed consent to participate in the study. However, three of them lack urine sample and one lacks serum sample. Thus, finally 65 pregnant women were included in the study.

\subsection{Study Area and Population}

The study area, Demba Gofa district, is located about 530 Kilo meters southwest of Addis Ababa. Sawla is a town where the administrative offices of Demba Gofa district are found. The altitude of the district is about $1500 \mathrm{~m}$ above sea level. The staple foods in the area include maize, teff, sorghum, sweet potato, cassava, enset, M. stenopetala, and peanut.

\subsection{Inclusion and Exclusion Criteria}

Pregnant women who were attending ANC at Sawla Health Center from Sawla town, Demba Gofa district and other adjoining districts, age $\geq 18$ years, and lived for at least six months in the study area were included in this study. Women with endocrine disorders (e.g. diabetes mellitus), subjects taking medications that affect thyroid function test, alcoholics, smokers, and subjects with Non-thyroidal illnesses (e.g. renal failure and liver disease) were excluded from the study.

\subsection{Sample Collection}

Between 3 - $5 \mathrm{ml}$ of blood was drawn from antecubital vein of the arm by trained laboratory technicians working at Sawla Health Center. The serum was separated after 45 minutes of collection by centrifugation at 3500 rpm for 15 minutes. Then, the serum was collected in a nanc tube and stored in refrigerator at the health center. Then it was transported to Addis Ababa packed in an ice box, and stored at $-20^{\circ} \mathrm{C}$ until analysis.

\subsection{Ethical Issues}

This study was approved by the Department of Biochemistry and Institutional Review Board (IRB) of the Faculty of Medicine, Addis Ababa University.

\subsection{Social and Anthropometric Data}

Age, residence, alcohol intake, fasting and smoking habit, and knowledge/habit of using iodized salt data were obtained using structured questionnaire. Height and weight were measured and expressed in meters and kilograms, respectively. Body mass index (BMI) was calculated by using weight in kilogram divided by square of height in meter $\left(\mathrm{kg} / \mathrm{m}^{2}\right)$. Blood pressure was measured after at least 5 minutes of rest using an appropriate mercury sphygmomanometer and expressed in mmHg. Morbidity data, history of thyroid disease and medication for thyroid disease (including thyroid surgery) were obtained using questionnaire.

\subsection{Consumption of Foods Containing Goitrogens}

Pregnant women who gave informed consent to partici- 
pate in the study were asked to fill a food frequency questionnaire (FFQ), which includes food items containing goitrogenic substances, particularly cassava and $M$. stenopetala. Women who were unable to fill the FFQ by their own were asked orally and their responses were filled on the questionnaire by the investigator.

\subsection{Biochemical Analysis}

The serum was analyzed for thyroid stimulating hormone (TSH), total thyroxine and total triiodothyronine in the Biochemistry laboratory at Addis Ababa University.

TSH: Serum TSH levels were measured using sandwich ELISA kit (Human Gesellschaft für Biochemica und Diagnostica mbH, Germany) as described by the manufacturer. This ELISA has an analytic sensitivity of $<0.10 \mathrm{mIU} / \mathrm{L} \mathrm{TSH}$. The absorbance of standards and specimens was determined by using ELISA microplate reader Anthos 2001 (Anthos labtec instruments Ges.m.b.H, Austria). The intensity of color is directly proportional to the concentration of TSH in the standards and samples.

Total T4 and total T3: The serum total T4 and total T3 were measured by using competitive ELISA kits (Human Gesellschaft för Biochemica und Diagnostica $\mathrm{mbH}$, Germany) as described by the manufacturer. The ELISA tests have analytic sensitivities of about $0.4 \mu \mathrm{g} / \mathrm{dl}$ $\mathrm{T} 4$ and $0.05 \mathrm{ng} / \mathrm{ml} \mathrm{T3}$. The absorbance of standards and specimens was determined by using ELISA microplate reader Anthos 2001 (Anthos labtec instruments Ges.m.b.H, Austria). The intensity of the color is inversely proportional to the amount of T4 and T3 in the standards and specimens.

\subsection{Statistical Analysis}

Excel data sheet and SPSS version 16.0 (Chicago, IL, USA) were used to analyze data obtained from questionnaire and laboratory analyses. The level of significance was set at $\mathrm{p}<0.05$.

\section{RESULTS}

\subsection{Study Subjects}

The mean age of the women was $24.7 \pm 3.9$ years. The women were grouped into three based on their gestation period, 7 women in first trimester, 26 women in second trimester and 32 women in third trimester. Most of the study subjects $(92.3 \%)$ were of Goffa ethnic group while the rest $(7.7 \%)$ constituted Amhara, Oromo, Hadiya, Wolyta, and Gamo ethnic groups. About $74 \%$ of the study subjects resided in Sawla town and the rest (26\%) were from the surrounding rural kebeles. Table 1 shows anthropometric and blood pressure of the women.

\subsection{Thyroid Function Tests}

Thyroid function parameters of the study subjects are shown in Table 2 . The median TSH value was decreased in second trimester compared to first trimester, and then it increased in third trimester. The TSH, T4 and T3 levels were tested for association to gestation period and found to be statistically non-significant (Figure 1).

Table 1. Range and mean of anthropometric and blood pressure.

\begin{tabular}{|c|c|c|}
\hline & Range & Mean (SD) \\
\hline Age (year) & $18.0-30.0$ & $24.7(3.9)$ \\
\hline Height (m) & $1.45-1.69$ & $1.57(0.06)$ \\
\hline Weight (kg) & $36.0-75.5$ & $57.2(7.3)$ \\
\hline BMI $\left(\mathrm{kg} / \mathrm{m}^{2}\right)$ & $16.7-30.4$ & $23.1(2.7)$ \\
\hline $\mathrm{SBP}(\mathrm{mmHg})$ & $90.0-120.0$ & $102.9(8.0)$ \\
\hline DBP (mmHg) & $60.0-90.0$ & $70.0(8.1)$ \\
\hline
\end{tabular}

$\mathrm{BMI}=$ body mass index, $\mathrm{SBP}=$ systolic blood pressure, $\mathrm{DBP}=$ diastolic blood pressure.

Table 2. Range and median $\left(25^{\text {th }}-75^{\text {th }} \%\right.$ interval $)$ values of thyroid function tests.

\begin{tabular}{|c|c|c|c|c|c|}
\hline & & $1^{\text {st }}$ trimester $(\mathrm{n}=7)$ & $2^{\text {nd }}$ trimester $(n=26)$ & $3^{\text {rd }}$ trimester $(\mathrm{n}=32)$ & $\mathrm{p}^{\sigma}$ \\
\hline \multirow{2}{*}{ TSH (mIU/L) (2) } & Range & $0.24-3.79$ & $0.03-7.47$ & $0.18-9.14$ & \multirow{2}{*}{ NS } \\
\hline & Median & $2.57(0.82-3.30)$ & $1.86(0.86-4.11)$ & $2.37(0.95-4.35$ & \\
\hline \multirow{2}{*}{$\mathrm{T} 4(\mu \mathrm{g} / \mathrm{dl})$} & Range & $7.8-16.0$ & $5.9-18.1$ & $3.8-19.0$ & \multirow{2}{*}{ NS } \\
\hline & Median & $9.8(8.4-13.9)$ & $10.0(8.0-14.2)$ & $10.3(8.7-13.0)$ & \\
\hline \multirow{2}{*}{ T3 (ng/ml) } & Range & $1.93-5.31$ & $0.71-3.71$ & $0.91-4.52$ & \multirow{2}{*}{ NS } \\
\hline & Median & $2.60(2.19-4.53)$ & $1.92(1.51-2.79)$ & $2.35(1.74-3.40)$ & \\
\hline
\end{tabular}

${ }^{\sigma}$ Kruskal-Wallis rank test, NS = non-significant. 


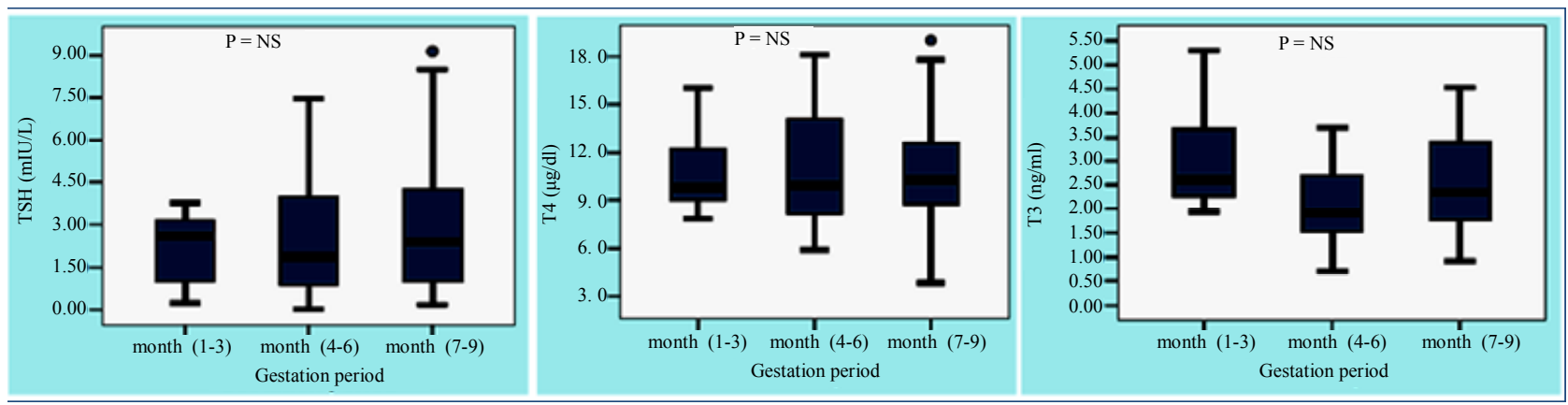

Figure 1. Box-Whisker of gestation period specific TSH, T4 and T3 levels (NS = Non-significan).

\subsection{Thyroid Function and Cassava Consumption}

The subjects were grouped into two based on cassava consumption. Those who eat cassava three and more than three times per week are considered as cassava consumers. Thyroid function parameters of cassava consumers and cassava non-consumers are presented in Table 3. Although there was slight increase of median TSH value for cassava consumers it was not statistically significant (Figure 2). For T4 and T3 there was decrease in median values in cassava consumers but still the decrease was not statically significant (Figure 2).

\subsection{Thyroid Function and Consumption of Moringa stenopetala}

The study subjects were also grouped into two based on Moringa stenopetala consumption. Those who eat $M$. stenopetala two or more than two times per day were assigned as $M$. stenopetala consumers. Table 4 shows thyroid function parameters of $M$. stenopetala consumers and non-consumers. For TSH the median value of consumers was greater than that of non-consumers but statistically non-significant (Figure 3). For T4 the median value was observed to decrease slightly in consumers and for T3 the median was slightly increased; but in both it was statistically non-significant (Figure 3).

\section{DISCUSSION}

Pregnancy is associated with change in thyroid physiology, including an increase in TBG that usually results in an increase in total T4 and total T3, a decrease in TSH levels related to increased production of $\mathrm{hCG}$, and an increase in renal clearance of iodine.

In this study, in all gestation period groups the median TSH and total T4 were within the normal reference intervals for non-pregnant women, provided with the test kit. The median total T3 values were greater than the upper limit of the reference interval of the test kit in first and third trimester while that of second trimester was within the reference interval. The median TSH decreased in second trimester and increased in third trimester. The decreased TSH in second trimester may be due to the increased production of hCG during pregnancy, which has thyrotropic activity. Different studies have shown that the plasma levels of hCG and TSH have reciprocal relationship [12]. Though the median total T4 values in each trimester were within the normal reference interval they were found to be elevated to the upper limit of the interval. The elevated total T4 levels may be due to increased levels of TBG during pregnancy. These results were comparable to results reported in studies in Sweden and Switzerland [27,28]. The increased total T3 may also be explained by the same reason of increased production of TBG.

Thyroid function will also be affected by goitrogenic substances in some plant foods. In this study it was tried to assess the effect of consumption of cassava and $M$. stenopetala. Though statistically non-significant it was observed that the median TSH level of women categorized as cassava consumers was slightly greater than that of non-consumers. In addition, the median values of total T4 and total T3 of cassava consumers were lower than those of non-consumers, but still statistically non-significant. These results indicate that cassava consumption may affect thyroid function of the population. The thiocyanate produced in the body from cyanogenic glucosides in cassava inhibits the uptake of iodine by the thyroid gland and thyroid peroxidase, thereby decreasing the formation of thyroid hormones. The decreased production of thyroid hormones in turn leads to stimulation of the pituitary gland to secrete $\mathrm{TSH}$, thus increasing plasma levels TSH. A previous study in the area has shown that the total goiter prevalence was increased with increasing cassava consumption [23].

Concerning consumption of $M$. stenopetala leaves, it was observed that the median values of TSH was increased in women categorized as $M$. stenopetala consumers compared to those categorized as non-consumers though the increment is statistically non-significant. The median total T4 value of $M$. stenopetala consumers was decreased compared to non-consumers. A composition 
Table 3. Range and median $\left(25^{\text {th }}-75^{\text {th }} \%\right.$ interval $)$ of thyroid function tests of cassava consumers and cassava non-consumers.

\begin{tabular}{ccccc}
\hline & & Cassava Consumers $(\mathrm{n}=26)$ & Cassava Non-consumers $(\mathrm{n}=39)$ & $\mathrm{p}^{\mathrm{\varepsilon}}$ \\
\hline \multirow{2}{*}{$\mathrm{TSH}(\mathrm{mIU} / \mathrm{L})(2)$} & Range & $0.03-6.93$ & $0.18-9.14$ & NS \\
& Median & $2.37(0.82-3.99)$ & $2.28(0.90-3.99)$ & $\mathrm{NS}$ \\
$\mathrm{T} 4(\mu \mathrm{g} / \mathrm{dl})$ & Range & $5.9-14.5$ & $3.8-19.0$ & $\mathrm{NS}$ \\
& Median & $9.3(8.1-12.5)$ & $0.2(8.5-14.1)$ & \\
$\mathrm{T} 3(\mathrm{ng} / \mathrm{ml})$ & Range & $0.93-3.38$ & $2.43(1.73-3.39)$ &
\end{tabular}

${ }^{£}$ Mann-Whitney two sample rank sum test.
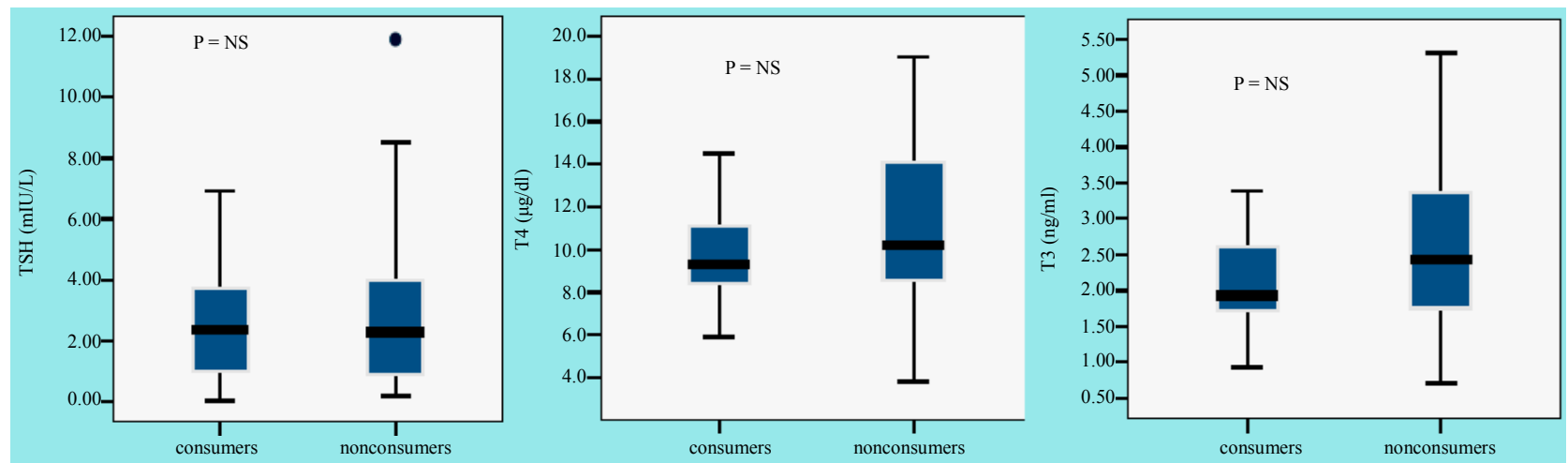

Figure 2. Box-Whisker of cassava intake specific TSH, T4 and T3 levels (NS = Non-significant).

Table 4. Range and median $\left(25^{\text {th }}-75^{\text {th }} \%\right.$ interval) of thyroid function tests of $M$. stenopetala consumers and M. stenopetala non-consumers.

\begin{tabular}{ccccc}
\hline & & M. stenopetal Consumers $(\mathrm{n}=31)$ & M. stenopetal Non-consumers $(\mathrm{n}=34)$ & $\mathrm{p}^{\mathrm{f}}$ \\
\hline \multirow{2}{*}{$\mathrm{TSH}(\mathrm{mIU} / \mathrm{L})(2)$} & Range & $0.03-8.52$ & $0.23-9.14$ & NS \\
& Median & $2.57(0.80-4.70)$ & $2.08(0.92-3.65)$ & NS \\
$\mathrm{T} 4(\mu \mathrm{g} / \mathrm{d})$ & Range & $6.0-19.0$ & $3.8-18.1$ & NS \\
& Median & $9.7(8.4-12.4)$ & $10.3(8.6-14.1)$ & $0.71-5.31$ \\
$\mathrm{~T} 3(\mathrm{ng} / \mathrm{ml})$ & Range & $0.71-5.31$ & $2.02(1.61-3.11)$ & \\
& Median & $2.44(1.79-3.37)$ & & \\
\hline
\end{tabular}

${ }^{£}$ Mann-Whitney two sample rank sum test.
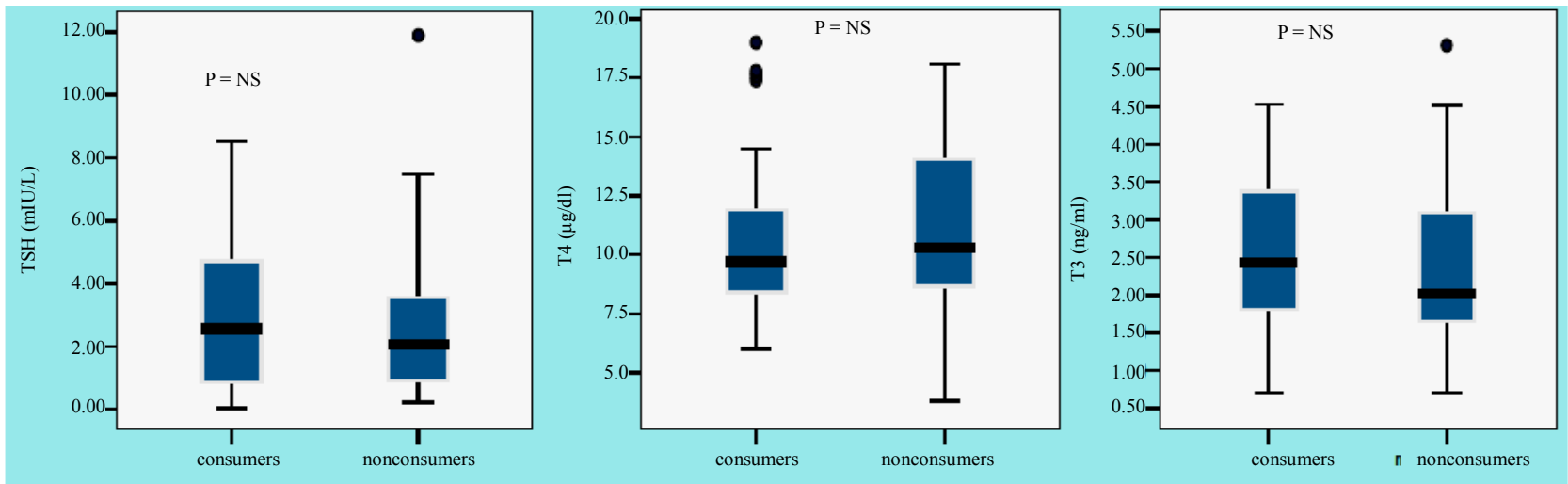

Figure 3. Box-Whisker of Moringa stenopetala intake TSH, T4 and T3 levels (NS = Non-significant). 
analysis study conducted on $M$. stenopetala leaves collected from the area has shown that M. stenopetala contains cyanogenic glucosides although the reported content was less than that expected to cause goiter [29]. In another study, it has been demonstrated that there is significant association between frequency of $M$. stenopetala consumption and prevalence of goiter [24]. Therefore, it can be presumed that frequent consumption of $M$. stenopetala leaves may lead to decreased production of thyroxine. This may aggravate the iodine deficiency problem in the study area.

The median T3 value of subjects M. stenopetala consumers was unexpectedly slightly greater than that of non-consumers. The elevated median levels of T3 of $M$. stenopetala consumers may possibly be due to the preferential production of $\mathrm{T} 3$ in the thyroid gland in conditions of decreased iodine availability.

\section{CONCLUSIONS AND RECOMMENDATION}

The study subjects have normal thyroid function as the median values of TSH and total T4 were within the reference interval of the test kit. The median values of total $\mathrm{T} 4$ and total T3 were elevated, which may be due to increased secretion of TBG. Therefore, it is important if trimester-specific reference intervals are established for our population and applied to interpret thyroid function in pregnant women.

Frequent consumption of cassava and M. stenopetala may also affect thyroid function of the study subjects. To reduce the goitrogenic effects of cassava and M. stenopetala, elaborative processing of these foods before consumption is recommended. Further study on the effect of cassava consumption on thyroid function is also important.

\section{REFERENCES}

[1] Johnson, L.R. (2003) Essential medical physiology. 3rd Edition, Elsevier Academic Press, Philadelphia, 587-605.

[2] Guyton, A.C. and Hall, J.E. (2006) Text book of medical physiology. 11th Edition, Elsevier Inc., Philadelphia, 931943.

[3] Arneson, W. and Brickell, J. (2007) Clinical chemistryA laboratory perspective. F.A. Davis Company, Philadelphia.

[4] Versloot, P.M., Schroder-van der elst, J.P., Van der heide, D., et al. (1997) Effects of marginal iodine deficiency during pregnancy: Iodide uptake by the maternal and fetal thyroid. American Journal of Physiology, Endocrinology and Metabolism, 273, 1121-126.

[5] Glinoer, D. (1997) The regulation of thyroid function in pregnancy: Pathways of endocrine adaptation from physiology to pathology. Endocrine Reviews, 18, 404-433. http://dx.doi.org/10.1210/er.18.3.404

[6] Shankar, P., Kilvert, A. and Fox, C. (2001) Changing thyroid status related to pregnancy. Postgraduate Medical Journal, 77, 591-592.

http://dx.doi.org/10.1210/er.18.3.404

[7] Kasper, D.L., Braunwald, E., Fauci, A.S., et al. (2005) Harisson's principles of internal medicine. 16th Edition, McGraw-Hill Companies. Inc., Boston, 2104-2126.

[8] Zigman, J.M., Cohen, S.E. and Garber, J.R. (2003) Impact of thyroxine-binding globulin on thyroid hormone economy during pregnancy. Thyroid, 13, 1169-1175. http://dx.doi.org/10.1210/er.18.3.404

[9] Sparre, L.S., Brundin, J., Carlstrom, K. and Carlstrom, A. (1987) Oestrogen and thyroxine-binding globulin levels in early normal pregnancy. Acta Endocrinology, 114, 298-230.

[10] Fantz, C.R., Dagogo-Jack, S., Ladenson, J.H. and Gronowski, A.M. (1999) Thyroid function during pregnancy. Clinical Chemistry, 45, 2250-2258.

[11] Burrow, G.N., Fisher, D.A. and Larsen, P.R. (1994) Maternal and fetal thyroid function. New England Journal of Medicine, 331, 1072-1078. http://dx.doi.org/10.1056/NEJM199410203311608

[12] Glinoer, D., De Nayer, P., Bourdoux, P., et al. (1990) Regulation of maternal thyroid during pregnancy. Journal of Clinical Endocrinology Metabolism, 71, 276-287. http://dx.doi.org/10.1210/jcem-71-2-276

[13] Hershman, J.M. (2008) The role of human chorionic gonadotropin as a thyroid stimulator in normal pregnancy. Journal of Clinical Endocrinology and Metabolism, 93, 3305-3306. http://dx.doi.org/10.1210/jc.2008-1461

[14] Arturi, F., Presta, I., Scarpelli, D., et al. (2002) Stimulation of iodide uptake by human chorionic gonadotropin in FRTL-5 cells: Effects on sodium/iodide symporter gene and protein expression. European Journal of Endocrinology, 147, 655-661. http://dx.doi.org/10.1530/eje.0.1470655

[15] Rodien, P., Bremont, C., Sanson, M.L., et al. (1998) Familial gestational hyperthyroidism caused by a mutant thyrotropin receptor hypersensitive to human chorionic gonadotropin. New England Journal of Medicine, 339, 1823-1826. http://dx.doi.org/10.1056/NEJM199812173392505

[16] Van Etten, C.H. (1969) Goitrogens. In: Liener, I.E., Ed., Toxic Constituents of Plant Foodstuffs, Academic Press Publications, New York, 103-142.

[17] Delange, F., Bourdoux, P., Colinet, E., et al. (1982) Nutritional factors involved in the goitrogenic action of cassava. In: Delange, F. and Ahluwalia, R., Eds., Cassava Toxicity and Thyroid: Research and Public Health Issues, International Development Research Centre (IDRC-207e), Ottawa, 17-26.

[18] Cardoso, A.P., Ernesto, M., Nicala, D., et al. (2004) Combination of cassava flour cyanide and urinary thiocyanide measurements of school children in Mozambique. International Journal of Food Science and Nutrition, 55, 183190. http://dx.doi.org/10.1080/09637480410001725265

[19] Ermans, A.M., Mbulamoko, N.M., Delange, F. and Ahlu- 
walia, R. (1980) Role of cassava in the etiology of endemic goiter and cretinism. International Development Research Center, Ottawa, 1-182.

[20] Chandra, A.K., Mukhopadhyay, S.S., Lahari, D. and Tripathy, S. (2004) Goitrogenic content of Indian cyanogenic plant foods and their in vitro anti-thyroidal activity. Indian Journal of Medical Research, 119, 180-185.

[21] Virion, A., Deme, D., Pommier, J. and Nunez, J. (1980) Opposite effect of thiocyanate on tyrosine iodination and thyroid hormone synthesis. European Journal of Biochemistry, 112, 1-7. http://dx.doi.org/10.1111/j.1432-1033.1980.tb04979.x

[22] Wolde-Gebriel, Z., Demeke, T., West C.E. and Van Der, H. (1993) Goiter in Ethiopia. British Journal of Nutrition, 69, 257-268.

http://dx.doi.org/10.1079/BJN19930027

[23] Cherinet, A., Kelbessa, U. and Wolde-Gebriel, S. (1998) Health effects of cassava consumption in south Ethiopia. East African Medical Journal, 75, 166-170.

[24] Cherinet, A., Omwega, A.M. and Imungi, J.K. (1999) Familial tendency and dietary association of goiter in Gamo-Gofa, Ethiopia. East African Medical Journal, 76, 447-451.
[25] Ewnetu, W. and Jemal, A. (1990) Normal thyroid function values in Ethiopians. Ethiopian Medical Journal, 28, 139-143.

[26] Cherinet, A., Gonfa, A., Melaku, U., et al. (2000) Thyroid responses to varying doses of oral iodized oil in school children in Awassa, Ethiopia. Ethiopian Journal of Health Development, 14, 49-55.

[27] Soldin, O.P., Hilakivi-Clarke, L., Weiderpass, E. and Soldin, S.J. (2004) Trimester-specific reference intervals for thyroxine and triiodothyronine in pregnancy in iodine sufficient women using isotope dilution tandem mass spectrometry and immunoassays. Clinica Chemica Acta, 349, 181-189. http://dx.doi.org/10.1016/j.cccn.2004.06.021

[28] Stricker, Rt., Echenard, M., Eberhart, R., et al. (2007) Evaluation of maternal thyroid function during pregnancy: The importance of using gestational age-specific reference intervals. European Journal of Endocrinology, 157, 509-514. http://dx.doi.org/10.1530/EJE-07-0249

[29] Cherinet, A., Kelbessa, U., Knapp, H., et al. (2003) A compositional study of Moringa stenopetala Leaves. East African Medical Journal, 80, 247-252. 